GENE 03565

\title{
Isolation and sequence analysis of CDC43, a gene involved in the control of cell polarity in Saccharomyces cerevisiae
}

(Recombinant DNA; yeast; cell-division cycle; bud emergence; helix-turn-helix; DNA-binding proteins)

\author{
Douglas I. Johnson ${ }^{a, b}$, Jeanne M. O'Brien* and Charles W. Jacobs ${ }^{\text {,** }}$ \\ a Department of Microbiology and Molecular Genetics, University of Vermont, Burlington, VT 0540S (U.S.A.) and ' Department of Biology. The \\ University of Michigan, Ann Arbor, MI 48109 (U.S.A.)
}

Received by J. Marmur: 16 December 1989

Accepted: 21 February 1990

\section{SUMMARY}

The Saccharomyces cerevisiae CDC43 gene product is involved in establishing cell polarity during the cell-division cycle. When grown at restrictive temperatures, temperature-sensitive $c d c 43$ mutants are unable to form buds and display delocalized cell-surface deposition [Adams et al., J. Cell Biol. (1990) in press]. We have isolated a cdc43-complementing plasmid from a yeast genomic-DNA library and localized the $C D C 43$ gene, by subcloning and transposon-mutagenesis experiments, to a 1.2-kb region of DNA that contained only one significant ATG-initiated open reading frame of 213 codons. The putative CDC43 gene product contains a possible nuclear-localization signal sequence, a cysteine-rich domain and a histidine-rich domain, and a region that is similar in structure to $\alpha$-helix-turn- $\alpha$-helix structurai domains present in some prokaryotic and cukaryotic DNA-binding proteins.

\section{INTRODUCTION}

The $S$. cerevisiae $C D C 24, C D C 42$, and $C D C 43$ gene products are involved in the development of cell polarity and the localization of secretion and cell-surface deposition during the yeast cell cycle (Hartwell et al., 1974; Sloat et al., 1981; Adams et al., 1990; Johnson and Pringle, 1990). Yeast strains containing lethal ts mutations in these genes

Correspondence tc: Dr. D.I. Johnson, Department of Microbiology and Molecular Genetics, University of Vermont, A-191 Given Building, Burlington, VT 05405 (U.S.A.) Tel. (802)656-8203; Fax (802)656-8584.

* Present address: Department of Biology, Albion College, Albion, MI 49224 (U.S.A.) Tel. (517)629-0388.

Abbreviations: aa, amino acid(s); bp, base pair(s); $C D C$, gene(s) controlling cell-division cycle; $k b, 1000 \mathrm{bp} ; \mathrm{mTn}$, minitransposon; ORF, open zeading frame; ori, origin of DNA replication; Pollk, Klenow (large) fragment of $E$. coli DNA polymerase I; S., Saccharomyces; SDS, sodium dodecyl sulfate; SSPE, $0.18 \mathrm{M} \mathrm{NaCl} / 0.01 \mathrm{M}$ Na.phosphate/0.001 M EDTA pH 7.4; Tn, transposnat; ts (Ts), temperature-sensitive. are unable to bud when grown at restrictive temperature, but their nuclear cycles continue along with an increase in cell mass and volume, resulting in greatly enlarged, multinucleate, unbudded cells. The cytoplasmic actin networks appear disorganized (Adams and Pringle, 1984), and chitin and other cell-surface materials appear to be deposited randomly or uniformly throughout the enlarging cell walls. The abnormal positioning of budding sites associated with some $c d c 24$ mutants and with overexpression of the CDC42 gene product suggests that these gene products are involved in the initial selection and organization of the budding site.

There is genetic evidence to suggest that the CDC24, $C D C 42$, and $C D C 43$ gene products interact within the cell. Strains containing ts mutations in both $C D C 42$ and $C D C 43$ are inviable when grown at their normal permissive temperature of $23^{\circ} \mathrm{C}$ (Adams et al., 1990). In addition, the $C D C 42$ gene, when present on a multicopy plasmid, is able to suppress a cdc24 ts mutation (Bender and Pringle, 1989).

The identification of a cdc24 mutant among a set of $\mathrm{Ca}^{2+}$-sensitive mutants (Ohya et al., 1986) and the finding 
that the predicted CDC24 gene product contains two putative $\mathrm{Ca}^{2+}$-binding domains (Miyamoto et al., 1987) suggest a possible interaction of this gene product with $\mathrm{Ca}^{2+}$. In contrast, CDC42 is a member of the rho family (Madaule et al., 1987) of ras-related genes; its product is predicted both to bind and hydrolyze GTP and to undergo C-terminal modification leading to membrane association (Johnson and Pringle, 1990).

In the hope of gaining further insight into the mechanisms of polarity establishment and budding in yeast, we have attempted to clone and sequence the $C D C 43$ gene. Although no strong conclusions can be drawn from the predicted aa sequence of the $C D C 43$ gene product, the results raise the possibilities that this gene product may be localized to the nucleus and perhaps involved in the regulation of gene expression.

\section{MATERIALS AND METHODS}

\section{(a) Reagents}

Enzymes, M13 dideoxy-sequencing kits, and other reagents were obtained from standard commercial sources and used according to the suppliers' specifications. $\left[\alpha-{ }^{35}\right.$ S $]$ dATP and $\left[\alpha-{ }^{32}\right.$ P]dATP were obtained from Amersham (Arlington Heights, IL).

\section{(b) Media, growth conditions, strains and plasmids}

Conditions for the growth and maintenance of bacterial and yeast strains have been described (Maniatis et al., 1982; Lillie and Pringle, 1980; Sherman et al., 1986). The permissive and restrictive temperatures for growth of ts mutants were $21^{\circ} \mathrm{C}$ and $36^{\circ} \mathrm{C}$, respectively. Escherichia coll strain HB101 was routinely used as a plasmid host. The $S$. cerevisiae strains used were TD4, MATa ura3 his4 lew2 trpl gal2, and TD1, MATa ura3 his4 trpl gal2 (both provided by G.R. Fink); JPT198BD4-4A, MATa cdc43-2

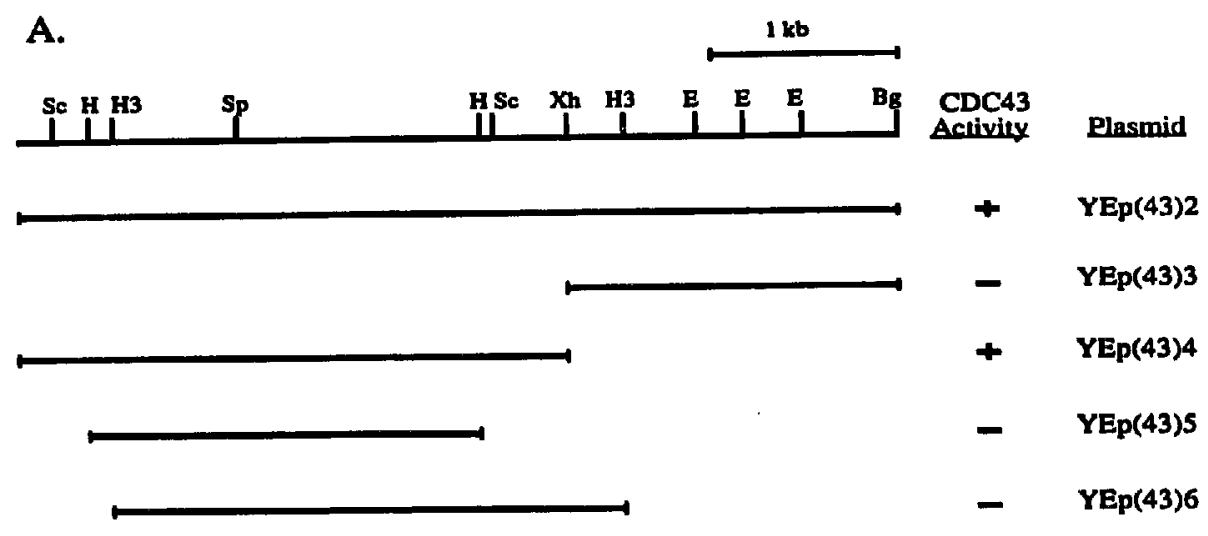

B.

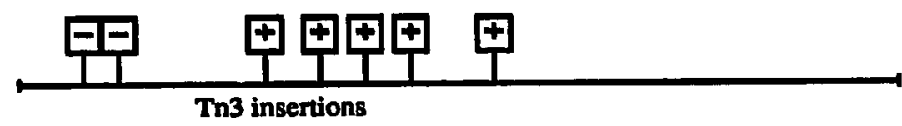

Fig. 1. Delimitation of the $C D C 43$ gene. (A) Restriction maps of the CDC43 region and of the inserts of plasmids discussed in RESULTS AND DISCUSSION, sections a, b, c. Standard procedures were used for recombinant-DNA manipulations (Maniatis et al., 1982), E. coli and yeast transformations (Maniatis et al., 1982; Sherman et al., 1986), and plasmid isolation from E. coll (Birnboim and Doly, 1979) and yeast (Sherman et al., 1986). YEp(43)2 was constructed by deleting an $\simeq 4 \cdot \mathrm{kb}$ BglII-Sall fragment (the Sall site was in the YEp24 vector) from YEp(43)1 (see RESULTS AND DISCUSSION, section a) by digesting with BglII and SalI, blunting with Pollk, and religating to regenerate a BglII site. YEp(43)3 was constructed by deleting the 3-kb Xhol-Nhel fragment from YEp(43)2 by digestion with Xhol + Nhel (the Nhel site was in the YEp24 vector), blunting with Pollk, and religating. YEp(43)4 was constructed by deleting the 1.8-kb Xhol-Bglll fragment from YEp(43)2 by digestion with XhoI + BglII, blunting with Pollk, and religating. YEp(43)5 was constructed by inserting the 2.2-kb HpaI fragment from YEp(43)2 into Pvull-digested YEp24. YEp(43)6 was constructed by inserting the 2.7-kb HindIII fragment from YEp(43)2 into HindllI-digested YEp103. The cdc43-complementing activity of each plasmid was determined by streaking plasmid-containing $\mathrm{CJ} 198-2 \mathrm{~B}$ cells onto YEPD plates at $36^{\circ} \mathrm{C}$; a plus symbol indicates essentially uniform growth at $36^{\circ} \mathrm{C}$; a minus symbol indicates no growth at $36^{\circ} \mathrm{C}$. Bg, BglII; E, EcoRI; H, HpaI; H3, HindIII; Sc, ScaI; Sp, SpeI; Xh, Xhol. All sites are shown for each enzyme. (B) Sites of mTn3(URA3) insertions. The mTn3(URA3) (Seifert et al., 1986) was used for insertional inactivation of the CDC43 gene. A 2.2-kb EcoRI fragment from YEp24 containing the $2 \mu$ plasmid ori was inserted into the unique $E c o R I$ site of plasmid pHSS6 (Seifert et al., 1986) to generate plasmid pHSS6 $+2 \mu$. A 4.8-kb Smal + BglII fragment from YEp(43)2 (see part A; the SmaI site is in the YEp24 vector) was inserted into SmaI + BamHI-cleaved pHSS6 + $2 \mu$ to generate plasmid pHSS $6+2 \mu(43)$. After co-transformation of pHSS6 $+2 \mu(43)$ and an mTn3(URA3)-containing plasmid into the appropriate $E$. coli strain (Seifert et al., 1986), cells that contained an mTn3(URA3) inserted into pHSS6 $+2 \mu(43)$ were selected. The locations and orientations of the insertions were then determined relative to the Xhol and EcoRI sites of pHSS $6+2 \mu(43)$ by restriction-enzyme analysis (data not shown; see RESULTS AND DISCUSSION, section b). Sites of $\mathrm{mTn} 3(U R A 3)$ insertions that did $(-)$ or did not $(+)$ inactivate cdo43-complementing activity are shown; the scale is the same as in part $A$. 
(Adams et al., 1990; a segregant from the fourth backcross of JPT198 to C276-4A and C276-4B); and CJ198-2B, MATa cdc43-2 ura3 trpl (constructed by crossing JPT198BD4-4A to TD1). Plasmids pBR322 and YEp24 have been described elsewhere (Maniatis et al., 1982; Botstein et al., 1979). The yeast-E. coli shuttle plasmid YEp103 contains the URA3 selectable yeast marker and the $2 \mu$ plasmid ori (S. Lillie, personal communication). The yeast genomic-DNA library in plasmid YEp24 (provided by D. Botstein) contains fragments produced by partial Sau3A digestion of DNA from $S$. cerevisiae strain DBY939 (Carlson and Botstein, 1982).

\section{RESULTS AND DISCUSSION}

(a) Isolation and identification of $C D C 43$

A plasmid that complemented the $c d c 43-2$ ts mutation in strain CJ 198-2B was isolated from a yeast genomic-DNA

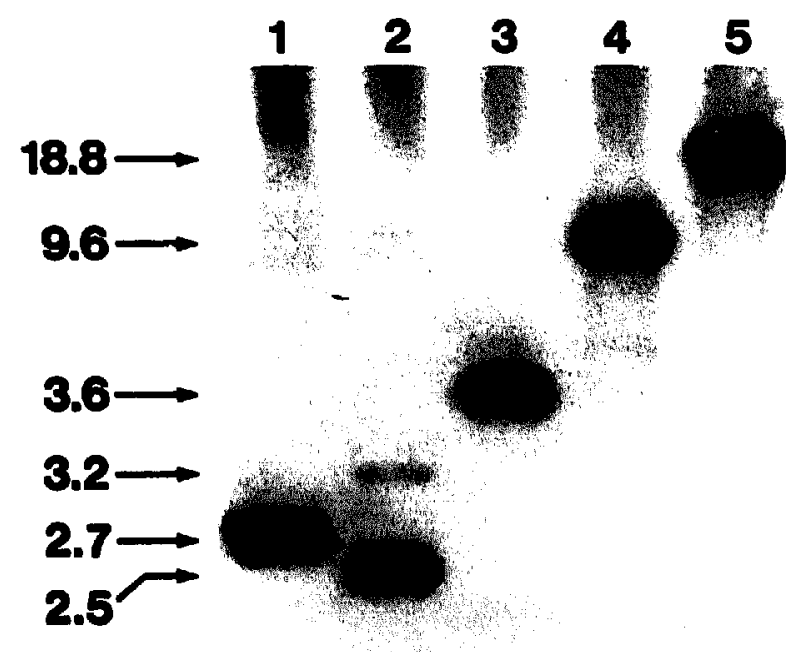

Fig. 2. DNA-DNA blot-hybridization analysis of chromosomal DNA from parental and transformed strains. Total yeast DNA was isolated essentially as described previously (Bloom and Carbon, 1982). DNA blot hybridizations were performed using $1 \%$ agarose gels and nitrocellulose paper (Maniatis et al., 1982). The DNA-DNA hybridizations were performed at $65^{\circ} \mathrm{C}$ for $\simeq 16 \mathrm{~h}$ in a solution containing $5 \times$ SSPE buffer (Maniatis et al., 1982) and 1\% SDS. After digestion with the indicated restriction enzymes, DNA fragments were separated and hybridized to a radioactively labeled probe. The probe was single-stranded DNA prepared by primer extension in the presence of $\left[\alpha .{ }^{32} \mathrm{P}\right]$ dATP on a M13mp19 template containing DNA between the SpeI and Xhol sites of YEp(43)2 (Fig. 1A). The sizes of the fragments are indicated in $\mathrm{kb}$ on left margin. Total DNA from strain TD4 (lanes 1-4) and from the same strain after integration of the 9.3-kb plasmid containing cdc43-complementing sequences and the URA3 gene (RESULTS AND DISCUSSION, section a, lane 5) was digested with HindIII (lane 1), Scal (lane 2), SpeI + BgllI (lane 3), and BglII (lanes 4 and 5). As the integrated vector sequence contains no BglII sites, the replacement of the original 9.6-kb BgllI fragment (lane 4) with an 18.8-kb Bglll fragment in the transformant (lane 5) indicates that the integration of the 9.3-kb plasmid had occurred at the chromosomal site homologous to the cdc43-complementing DNA. library in the URA3-containing plasmid YEp24. From a primary Ura ${ }^{+} \mathrm{Ts}^{+}$yeast transformant, a plasmid [designated YEp(43)1] was recovered into $E$. coli that could retransform CJ198-2B to Ura ${ }^{+} \mathrm{Ts}^{+}$. The $\mathrm{Ura}^{+}$and $\mathrm{Ts}^{+}$ phenotypes of these transformants co-segregated after growth on nonselective media (data not shown), indicating that the complementation of $c d c 43-2$ was indeed due to the autonomously replicating recombinant plasmid. Plasmid YEp(43)1 contained an $\simeq 8$-kb insert (data not shown). Digestion and religation of $Y E p(43) 1$, as described in the legend to Fig. 1, yielded YEp(43)2, which was used in all subsequent experiments. A DNA-DNA blot-hybridization experiment using total yeast DNA and an appropriate probe revealed only the fragments expected if the cloned DNA was derived without rearrangernent from contiguous chromosomal DNA that was single copy in the haploid genome (Fig. 2, lanes 1-4).

To test the identity of the cloned DNA, we integrated a plasmid containing the $c d c 43$-complementing sequences and the yeast selectable marker URA3 into a $C D C 43$ yeast strain, and then determined the meiotic linkage between the integrated URA3 gene and a $c d c 43$ mutation. A 5-kb EcoRI fragment (one of the EcoRI sites was in the YEp24 vector) containing the cdc43-complementing region and the URA3 gene was subcloned from YEp(43)2 into the EcoRI site of pBR322 (which cannot replicate autonomously in yeast). The resulting plasmid was linearized within the insert at the unique XhoI site and transformed into strain TD4, selecting for Ura ${ }^{+}$. Two stable Ura ${ }^{+}$transformants were shown by DNA-DNA blot hybridization to have the plasmid integrated at the chromosomal site homologous to the cdc43complementing DNA (Fig. 2, lane 5; only one transformant is shown). These transformants were crossed to the cdc43-2 strain CJ198-2B. Of 22 four-spore tetrads, 22 were parental ditypes (2 $\mathrm{Ura}^{+} \mathrm{Ts}^{+}: 2 \mathrm{Ura}^{-} \mathrm{Ts}^{-}$), showing tight linkage between the $c d c 43$ mutation and the integrated URA3 gene. Thus, integration had been directed to the $C D C 43$ locus, suggesting that the cdc43-complementing activity is due to the bona fide $C D C 43$ gene.

\section{(b) Localization of $C D C 43$ on the complementing DNA}

To localize the $C D C 43$ gene, subclones were constructed as described in Fig. 1A, legend. Complementation of the cdc43-2 mutation by plasmid YEp(43)4 but not by plasmids YEp(43)3, YEp(43)5, and YEp(43)6 indicated that CDC43 lies within the 3-kb region to the left of the XhoI site, overlaps the left-hand HindIII site and one or both of the $H p a I$ sites. $C D C 43$ was also localized by determining the sites at which transposon insertion could inactivate cac43complementing activity. Transposon-containing plasmids were collected and the sites of insertion were determined by restriction analyses (Fig. 1B, legend). These plasmids were then tested for $c d c 43$-complementing activity in strain 
ATG TGT GAA GCT ACC AAT GGC CCG AGT AGA GTT GTG ACT AAA AAG CAT AGG AAA TTT TTC Het Cys Gin Ala Thr Asn Gly Pro Ser Arg Val Val Thr Lys lys his arg Lys phe Phe

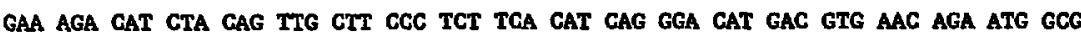
glu Arg his Leu Gln Leu Leu Pro Ser Ser His Gln Gly His Asp Val Asn Arg Met Ala

ATA ATA TTC TAC TCA ATC TCA GGA CTC TCT ATA TTT GAT GIT AaC GTT TCT GCG Aag TAC Ile Ile Phe Tyr Ser Ile Ser Gly Leu Ser Ile Phe Asp Val Asn Val Ser Ala Lys Tyr

GGC GAT GAT CIT GGC TGG ATG CGG AAA GAT TAT ATC AAA ACA GTG CTG GAT GAT ACA GAA Gly Asp His Leu Gly Trp Ket Arg Lys His Tyr Ile Lys Thr Val Leu Asp Asp Thr Glu

AAT ACT GTG ATA TCT GGA TTT GIT GGA AGC TTA GTC ATG AAT ATC CCT GAC GCA ACA ACC Asn Thr Val Ile Ser Gly Phe Val Gly Ser Leu Val Met Asn Ile Ero His Ala Thr Thr

ATT AAT CTA CCA AAT ACT CTC TTT GGA TTG TTG TCC ATG ATT ATG CTG AGA GAT TAC GAG Ile Asn leu Pro Asn Thr Leu Phe Ala Lou Leu Ser Met Ile Met Leu Arg Asp Tyr Glu

TAT TTT GAG ACT ATA CTA GAC AAA AGA AGC CTG GCG AGA TTT GTT TCT AAg TGC CAA CGA Tyr Phe Glu Thr Ile Leu Asp Lys Arg Ser Leu Ala Arg Phe Val. Ser Iys Cys Gln Arg

CCT GAC CGT GGC TCG TTT GTA TCT TGT TTA GAC TAT AAG ACA AAT TGT GGA TCT TCG GTT Pro Asp Arg Gly Ser Phe Val Ser Cys Leu Asp Tyr Lys Thr Asn Cys Gly Ser Ser Val

GAT TCA GAC GAT ITA AGg TTT TGC TAC ATC GCA GTT GCC ATT CTG TAC ATA TGC GGA TGC Asp Ser Asp Asp Leu Arg Phe Cys Tyr Ile Ala Val Ala Ile Leu Tyr Ile Cys Gly Cys

CGA TCC AAA GAA GAC TTT GAT GAA TAC ATT GAT ACT GAG AAG TTG CTT GGC TAT ATA ATC Arg Ser Lys Glu Asp Phe Asp Glu Tyr Ile Asp Thr Glu Lys Leu Leu Gly Tyr Ile Met

TCG CAA GAA TGC TAC AAC GGA GCT TTC GGT GCC CAC CAA TGA Ser Gln Gln Cys Tyr Asn Gly Ala Phe Gly Ala Hls Gln End

ACCACACTCA GGGTACACAT CTTGTGCGCT GTCTACCTTA GCTTTACTTC TCTAGTTTGG AAAAGCTATC AGACAAGTTT AAGAAGACAC CATAACCTGG CTATTACATA GGCAAGTATC AAGCCATGGA TGTATGAAAT TTGAAAGCGA ATTGAATGCC AGCTATCATC AATCTGATGA TGGCGGTITC CAGGGAAGGG AGAACAAGT CGCTGATACG TGTTACGCAT TTTGGTGCTT AAATTCACTA CACTTACTAA CAAAGGATTG GAAAATGCTA TGCCAAACTG AACTACT

Fig. 3. Nucleotide sequence of the CDC43 region and predicted aa sequence of the CDC43 product. M13 dideoxy sequencing (Sanger et al., 1977) was performed essentially as described in the Sequenase ${ }^{\mathrm{TM}}$ sequencing manual of the United States Biochemicals Corp. (Cleveland, OH), using [ $\alpha-{ }^{35}$ S]dATP and the vectors M13mp18 and M13mp19. Sequencing primers were provided by E.I. DuPont de Nemours \& Co., Inc. (Wilmington, DE) and Dr. John Burke (Department of Microbiology and Molecular Genetics, University of Vermont, VA). Sequences were analyzed using the University of Wisconsin Genetics Computer Group (Madison, WI) sequence analysis programs. The aa sequence similarities were determined using the Pustell sequence analysis programs (IBI, New Haven, CT). The nt sequence is numbered relative to the A of the putative start codon. The ScaI, $H$ pal, and $H i n d I I I$ sites (indicated with solid lines) are located at nt -42 to $-37,+160$ to +165 , and +267 to +272 , respectively. Possible TATA promoter sequences (indicated with dashed lines) are present at $\mathrm{nt}-121$ to -126 and -76 to -71 . In addition, a 14 bp stretch of poly(dA-dT) is present at $n t-224$ to -211 . Similar stretches of poly(dA-dT) have been implicated in the constitutive expression of certain promoters (Struhl, 1986). The underlined aa sequence is similar to the $\alpha$-helix-turn- $\alpha$-helix structural motif (RESULTS AND DISCIJSSION, section c). GenBank accession number is M31114.

CJ198-2B. The results (Fig. 1B) suggested that the CDC43 gene lies within a 1.2-kb region lying to the left of the SpeI site.

\section{(c) Analysis of CDC43 nt sequence and deduced aa se- quence}

The 3-kb region to the left of the XhoI site (Fig. 1A) was inserted into SmaI + Sall-digested M13mpl8 and M13mp19 using the unique SmaI and XhoI sites in YEp(43)2 (Fig. 1A; the SmaI site was in the YEp24 vector). These phages were then used in dideoxy-sequencing reactions. Both strands of the $c d c 43$-complementing region to the left of the SpeI site (Fig. 1A) were completely sequenced (Fig. 3). The sequence revealed the presence of only one significant, ATG-initiated ORF that spanned both of the left-hand HindIII and left-hand HpaI sites (Fig. 1A).
Thus, this 213-codon ORF presumably encodes the $C D C 43$ gene product. The absence of a TACTAAC consensus splicing sequence (Langford et al., 1984) suggests a lack of introns.

The predicted $C D C 43$ product is a 213-aa polypeptide with an $M_{\mathrm{r}}$ of 24266 and a net charge of +1 (Fig. 3). Comparison of the predicted aa sequence with the National Biomedical Research Foundation protein database and the GenBank DNA/protein database revealed no significant similarities to any known proteins. However, there are several features of the predicted aa sequence that are potentially informative. First, a sequence similar to known or suspected nuclear-localization signal sequences is present at aa 13-18 (Fig. 4). This basic aa sequence is very similar to sequences that have been shown experimentally to be involved in the localization of proteins to the nucleus (Silver 
CDC43 (S. cerevisiae)

Large $\mathrm{T}$ antigen (SV40)

GAL4 (S. cerevisiae)

Histone 2B ( $S$. cerevisiae)
Lys Lys His Arg Lys ${ }^{18}$

Lys Lys Lys Arg Lys ${ }^{127}$

Lys Lys Leu Lys Cys'

Lys Lys Arg Ser Lys ${ }^{36}$

Fig. 4. A possible nuclear-localization signal sequence in $C D C 43$. Similarities between aa 13-18 of the predicted aa sequence of the $C D C 43$ gene product (see Fig. 3) and known or inferred nuclear-localization signal sequences of the SV40 large T antigen, the $S$. cerevisiae GAL4 gene product, and the $S$. cerevisiae histone 2B protein are shown (Silver and Goodman, 1989). The positions of these sequences in their respective proteins are indicated by the residue number for the last aa.

and Goodson, 1989). Second, separate His-rich and Cysrich aa domains with the sequences His- $\mathrm{Xxx}_{6}-\mathrm{His}_{-} \mathrm{X}_{\mathrm{xx}_{7}}$ His- $\mathrm{Xxx}_{2}$-His and Cys- $\mathrm{Xxx}_{10}-$ Cys- $\mathrm{Xxx}_{6}-\mathrm{Cys}-\mathrm{Xxx}_{11}$-Cys$\mathrm{Xxx}_{9}$-Cys-Xxx-Cys (Xxx is any aa) are present at aa 16-34 and 138-180, respectively (Fig. 3). These sequences show no strong resemblances to the $\mathrm{Cys}_{2} \mathrm{His}_{2}$ or $\mathrm{Cys}_{\mathrm{x}}$ zinc-finger domains implicated in the DNA binding of several eukaryotic regulatory proteins (Berg, 1988). While this does not necessarily preclude the possibility that these regions are involved in DNA binding, it is more likely that they are involved in some other aspect of protein function such as an interaction with metal ions (Szczypka and Thiele, 1989) or disulfide bridge formation. Third, a region of the predicted aa sequence (aa 55-76, Fig. 3) is similar to the $\alpha$-helix-turn- $\alpha$-helix structural motif found or inferred in a wide variety of prokaryotic and eukaryotic DNA-binding proteins (Brennan and Matthews, 1989). The CDC43 sequence contains a Gly ${ }^{65}$ residue along with hydrophilic residues at positions $57,59,62,63,68,69,70,73$, and 74 , and hydrophobic residues at positions $58,61,64,72,75$, and 76. This sequence would have the proper alignment of an residues that could allow the formation of a helix-turnhelix structure with nonpolar residues facing the hydrophobic core and exposed polar residues that could interact with DNA (Pabo and Sauer, 1984). Taken together, these inferred structural features raise the possibilities that the $C D C 43$ gene product is localized to the nucleus, interacts with metal ions, and binds to DNA.

\section{(d) Conclusions}

The CDC43 gene product is involved in the morphogenetic steps of the yeast cell cycle. To begin exploring CDC43 function at the molecular level, we have isolated and sequenced this gene. Although the inferred aa sequence of the CDC43 product allows no strong conclusions, it does provide some interesting and unexpected clues to possible functions of this protein.

(1) The presence of a possible nuclear-localization signal raises the possibility that the $C D C 43$ gene product performs its cell-cycle function within the nucleus. Testing of this possibility will depend on the use of CDC43-specific antibodies in immunofluorescence localization studies.

(2) The presence of an aa domain within $C D C 43$ that is similar to the $\alpha$-helix-turn- $\alpha$-helix structural motif found in some DNA-binding proteins raises the possibility that $C D C 43$ could interact with DNA in some manner. While it is clear that transcriptional regulation plays a part in the control of some CDC genes in yeast (Peterson et al., 1985; White et al., 1987), there is no evidence as yet for transcriptional regulation of CDC43 or any of the other genes whose products are involved in the control of cellular polarity. Thus, evaluation of the significance of this possible structural domain must await the results of studies of the possible transcriptional regulation of these genes.

The 'synthetic lethality' of $c d c 43 c d c 42$ double mutants suggests that these genes or their products interact within the cell. If the CDC43 gene product is in fact localized to the nucleus and interacts with DNA, it could be speculated that $C D C 43$ is involved in the transcriptional regulation of $C D C 42$. It is possible that the presence of a mutant $C D C 43$ gene product could lead to a change in the expression of $C D C 42$ in a $c d c 43$ cdc42 double mutant, thereby leading to a new lethal phenotype in these cells. This speculation should be testable by analyzing CDC42-specific mRNA levels in $c d c 43$ mutants.

\section{ACKNOWLEDGEMENTS}

We are indebted to John Pringle, in whose laboratory some of this work was performed, and we thank him and members of his laboratory for helpful discussions and comments on this paper. We also thank John Burke for providing oligodeoxyribonucleotide primers; Peter Miller, Gerard Bouffard, Brian Foley, and Chris Fenno for assistance in running computer programs; and David Pederson and John Burke for helpful discussions. This research was supported by National Science Foundation-VT EPSCOR grant R11-8610679 (University of Vermont, D.I.J.), grants from the American Cancer Society (Vermont Division) and the University of Vermont College of Medicine (D.I.J.), National Institutes of Health (NIH) grant GM 31006 (J.R. Pringle), and NIH postdoctoral fellowships GM 10913 (D.I.J.) and GM 09727 (C.W.J.).

\section{REFERENCES}

Adams, A.E.M. and Pringle, J.R.: Relationship of actin and tubulin distribution to bud growth in wild-type and morphogenetic-mutant Saccharomyces cerevisiae. J. Cell Biol. 98 (1984) 934-945.

Adams, A.E.M., Johnson, D.l., Longnecker, R.M., Sloat, B.F. and Pringle, J.R.: CDC42 and CDC43, two additional genes involved in budding and the establishment of cell polarity in the yeast Saccharomyces cerevisiae. J. Cell Biol. (1990) in press.

Bender, A. and Pringle, J.R.: Multicopy suppression of the cdc24 budding defect in yeast by $C D C 42$ and three newly identified genes including 
the ras-related RSRI gene. Proc. Natl, Acad. Sci. USA 86 (1989) 9976-9980.

Berg, J.M.: Proposed structure for the zinc-binding domains from transcription factor IIIA and related proteins. Proc. Natl. Acad. Sci. USA 85 (1988) 99-102.

Birnboim, H.C. and Doly, J.: A rapid alkaline extraction procedure for screening recombinant plasmid DNA. Nucleic Acids Res. 7 (1979) 1513-1523.

Bloom, K.S. and Carbon, J.: Yeast centromere DNA is in a unique and highly ordered structure in chromosomes and small circular minichromosomes. Cell 29 (1982) 305-317.

Botstein, D., Falco, S.C., Stewart, S.E., Brennan, M., Scherer, S., Stinchcomb, D.T., Struhl, K. and Davis, R.W.: Sterile host yeasts (SHY): a eukaryotic system of biological containment for recombinant DNA experiments. Gene 8 (1979) 17-24.

Brennan, R.G. and Matthews, B.W.: Structural basis of DNA-protein recognition. Trends Biochem. Sci. 14 (1989) 286-290.

Carlson, $M$. and Botstein, $D$.: Two differentially regulated $m R N A s$ with different $5^{\prime}$ ends encode secreted and intracellular forms of yeast invertase. Cell 28 (1982) 145-154.

Hartwell, L.H., Culotti, J., Pringle, J.R. and Reid, B.J.: Genetic control of the cell division cycle in yeast. Science 183 (1974) 46-57.

Johnson, D.I. and Pringle, J.R.: Molecular characterization of CDC42, a Saccharomyces cerevisiae gene involved in the development of cell polarity. J. Cell Biol. (1990) in press.

Langford, C.J., Klinz, F.-J., Donath, C. and Gallwitz, D.: Point mutations identify the conserved, intron-contained TACTAAC box as an essential splicing sequence in yeast. Cell 36 (1984) 645-653.

Lillie, S.H. and Pringle, J.R.: Reserve carbohydrate metabolism in Saccharomyces cerevisiae: responses to nutrient limitation. J. Bacteriol. 143 (1980) 1384-1394

Madaule, P., Axel, R. and Myers, A.M.: Characterization of two members of the rho gene family from the yeast Saccharomyces cerevisiae. Proc. Natl. Acad. Sci. USA 84 (1987) 779-783.

Maniatis, T., Fritsch, E.F. and Sambrook, J.i Molecular Cloning. A Laboratory Manual. Cold Spring Harbor Laboratory, Cold Spring Harbor, NY, 1982.
Miyamoto, S., Ohya, Y., Ohsumi, Y. and Anraku, Y.: Nucleotide sequence of the CLS4 (CDC24) gene of Saccharomyces cerevisiae. Gene 54 (1987) 125-132

Ohya, Y., Miyamoto, S., Ohsumi, Y. and Anraku, Y.: Calcium-sensitive cls4 mutant of Saccharomyces cerevisiae with a defect in bud formation. J. Bacteriol. 165 (1986) 28-33.

Pabo, C.O. and Sauer, R.T.: Protein-DNA recognition. Annu. Rev. Biochem. 53 (1984) 293-321.

Peterson, T.A., Prakash, L., Prakash, S., Osley, M.A. and Reed, S.I.: Regulation of CDC9, the Saccharomyces cerevisiae gene that encodes DNA ligase. Mol. Cell. Biol. 5 (1985) 226-235.

Sanger, F., Nicklen, S. and Coulson, A.R.: DNA sequencing with chainterminating inhibitors. Proc. Natl. Acad. Sci. USA 74 (1977) 5463-5467.

Seifert, H.S., Chen, E.Y., So, M. and Heffron, F.: Shuttle mutagenesis: a method of transposon mutagenesis for Saccharamyces cerevisiae. Proc. Natl. Acad. Sci. USA 83 (1986) 735-739.

Sherman, F., Fink, G.R. and Hicks, J.B.: Methods in Yeast Genetics. A Laboratory Manual. Cold Spring Harbor Laboratory, Cold Spring Harbor, NY, 1986.

Silver, P. and Goodson, H.: Nuclear protein transport. CRC Crit. Rev. Biochem. Mol. Biol. 24 (1989) 419-435.

Sloat, B.F., Adams, A, and Pringle, J.R.: Roles of the CDC24 gene product in cellular morphogenesis during the Saccharomyces cerevisiae cell cycle. J. Cell Biol. 89 (1981) 395-405.

Struhl, K.: Yeast promoters. In Reznikoff, W. and Gold, L. (Eds.), Maximizing Gene Expression. Butterworth, Boston, MA, 1986, pp. 35-78.

Szczypka, M.S. and Thiele, D.J.: A cysteine-rich nuclear protein activates yeast metallothionein gene transcription. Mol. Cell. Biol. 9 (1989) 421-429.

White, J.H.M., Green, S.R., Barker, D.G., Dumas, L.B. and Johnston, L.H.: The CDC8 transcript is cell cycle regulated in yeast and is expressed coordinately with $C D C 9$ and $C D C 21$ at a point preceding histone transcription. Exp. Cell Res. 171 (1987) 223-231. 